\title{
Cancer Screening of Long-Term Cancer Survivors
}

\author{
Jessica R. Schumacher, PhD, Whitney P. Witt, PhD, MPH, Mari Palta, PhD, \\ Noelle K. LoConte, MD, Susan M. Heidrich, PhD, RN, Amy Trentham-Dietz, PhD, \\ Nancy Pandhi, MD, MPH, and Maureen A. Smith, MD, MPH, PhD
}

Background: Although 64\% of cancer survivors are expected to live at least 5 years beyond diagnosis, the receipt of cancer screening by this population is unclear. The objective of this study was to assess the relation between a cancer diagnosis and future cancer screening, exploring provider-, patient-, and cancer-specific factors that explain observed relationships.

Methods: The Wisconsin Longitudinal Study (WLS) and Wisconsin Tumor Registry were used to identify 2 participant groups: 415 patients diagnosed with nonmetastatic cancer between 1992 to 1993 (before cancer) and 2003 to 2004 (after cancer) and 4680 controls (no cancer). Adjusted average predicted probabilities of cancer screening were estimated with models that first did not include and then included, provider (provider relationship length), participant (depressive symptoms per the Center for Epidemiologic Studies Depression Scale), and cancer-specific (time since diagnosis) factors. Participants with a history of cancer associated with a given screening test were then excluded to assess whether relationships are explained by screening for recurrence versus second cancers.

Results: Female cancer survivors were more likely than no-cancer controls to undergo pelvic/Papanicolaou screening (survivors: $70 \%, 95 \%$ confidence interval [CI]: $63 \%$ to $76 \%$; controls: $61 \%, 95 \%$ CI: $59 \%$ to $63 \%$ ) and mammography screening (survivors: $86 \%$, 95\% CI: $78 \%$ to $90 \%$; controls: $76 \%$, $95 \%$ CI: $74 \%$ to $77 \%$ ), though male cancer survivors were not more likely to receive prostate exams (survivors: $76 \%, 95 \%$ CI: $70 \%$ to $82 \%$; controls: $69 \%$, 95\% CI: $67 \%$ to $71 \%$ ). After excluding people with a history of the cancer being screened for, there were few significant differences in cancer screening between short- or long-term survivors ( $\geq 5$ years) and no-cancer controls. Relationships were not sensitive to adjustment for provider or participant factors.

Conclusions: The significant positive differences in cancer screening between people with and without cancer can be explained by screening for recurrence. Long-term cancer survivors are not more likely to receive follow-up screening for second cancers. This information should be used by providers to ensure patients receive recommended follow-up preventive care. (J Am Board Fam Med 2012;25:460 - 469.)

Keywords: Cancer Screening, Longitudinal Studies, Preventive Health Services, Prevention, Primary Health Care, Registries, Survivorship

Cancer detection and treatment advances have produced declining cancer death rates, ${ }^{1}$ with $64 \%$ of

This article was externally peer reviewed.

Submitted 11 April 2011; revised 14 February 2012; accepted 29 February 2012.

From the Department of Health Services Research, Management, and Policy, University of Florida, Gainesville (JRS); the Department of Population Health Sciences (WPW, MP, AT-D, NP, MAS), Department of Biostatistics and Medical Informatics (MP), Department of Medicine, Division of Hematology and Medical Oncology (NKL), Department of Family Medicine (NP, MAS), and Department of Surgery (MAS), University of Wisconsin, Madison, School of Medicine and Public Health, Madison; the University of Wisconsin Carbone Cancer Center, Madison (WPW, NKL, SMH, AT-D, MAS); and the University of Wisconsin, Madison, School of Nursing, Madison (SMH). cancer survivors expected to live $\geq 5$ years from diagnosis. $^{2}$ Despite improvements, cancer survivors

Funding: This work was supported by the Agency for Health care Research and Quality (AHRQ)/National Research Service Award (NRSA) T-32 Institutional Training Program (grant nuo. T32 HS00083); the National Cancer Institute (grant no. R21 CA137288); the National Institute on Aging (grant no. P01 AG021079); and the CommunityAcademic Partnerships core of the University of Wisconsin Institute for Clinical and Translational Research (UW ICTR), National Center for Research Resources, National Institutes of Health (grant no. UL1 RR025011). In addition, this project is supported by a National Institute on Aging Mentored Clinical Scientist Research Career Development Award (grant no. 1 K08 AG029527; NP). This project was further supported by the Health Innovation Program. This continued. . 
remain at risk of recurrence and second cancers. ${ }^{3}$ In recognition of these risks, the Institute of Medicine outlined a critical need to improve the long-term follow-up of cancer survivors, including cancer screening, to optimize health outcomes. ${ }^{4}$

Given long-term health risks, there is reason to believe cancer survivors would be likely to undergo recommended cancer screening, ${ }^{5}$ but evidence of whether this occurs is mixed. Several studies show cancer survivors to be more likely to receive mammograms, ${ }^{6-11}$ Papanicolaou smear/pelvic examinations, ${ }^{6-8}$ and prostate-specific antigen tests ${ }^{6,8}$ than adults without a personal history of cancer. Other studies found either no difference ${ }^{12}$ or underutilization of certain services once people with a history of the cancer being screened for were excluded. ${ }^{10,12}$ These studies were largely analyses of administrative datasets (eg, Surveillance, Epidemiology and End Results Reporting [SEER]-Medicare) and focused on recently diagnosed breast and colorectal cancer survivors older than age 65. This limits the ability to control for a comprehensive set of patient-level factors or explore mechanisms through which a cancer diagnosis influences screening behavior.

The amount of time a person has lived with cancer may influence cancer screening behavior. Surviving 5 years is considered a "milestone"13 that represents a reduction in health risks, ${ }^{13,14}$ though many long-term survivors remain at risk of recurrence and second cancers. Studies using SEERMedicare data suggest that mammography and cervical cancer screening decline after a diagnosis of breast and colorectal cancer., ${ }^{9,15}$ Cancer screening,

research uses data from the Wisconsin Longitudinal Study (WLS) of the University of Wisconsin-Madison. A public use file of data from the WLS is available at http://www.ssc. wisc.edu/wlsresearch/data/. Since 1991, the WLS has been supported principally by the National Institute on Aging (grant nos. R01 AG09775 and R01 AG033285), with additional support from the Vilas Estate Trust, the National Science Foundation, the Spencer Foundation, and the Graduate School of the University of Wisconsin-Madison.

Prior presentation: Portions of these results were presented at a National Research Service Award Trainees Research Conference sponsored by the Agency for Health care Research and Quality (AHRQ). Preliminary findings were presented at the Biennial Cancer Survivorship Research Conference, held June 17-19, 2010, Washington, DC.

Conflict of interest: none declared.

Corresponding author: Jessica Schumacher, $\mathrm{PhD}$, Department of Health Services Research, Management and Policy, College of Public Health and Health Professions, University of Florida, P.O. Box 100195, Gainesville, FL 32610-0195 (E-mail: jschumacher@phhp.ufl.edu). however, has not been described in individuals surviving longer than 5 years or compared with trends in people without cancer. Studies addressing this gap have important clinical implications. As the number of cancer survivors continues to increase, providers will need to remain vigilant in screening for recurrent and new cancers.

Research exploring factors that affect cancer screening has focused primarily on provider type and patient mental health. After 5 years from diagnosis, nearly two-thirds of cancer survivors visit their primary care physician (PCP) exclusively, ${ }^{15}$ making a shared care model for the systematic long-term care of cancer survivors less feasible. In primary care, continuity of care generally fosters patient adherence to physician recommendations for cancer-specific services, ${ }^{16,17}$ though this has not been explored for cancer survivors. Depressive symptoms are commonly reported by cancer survivors $^{18}$ and could be a modifiable mechanism by which a diagnosis impacts screening, though to our knowledge this has not been explored. Cross-sectional studies have yielded mixed results, with some studies associating depressive symptoms with underutilization ${ }^{19}$ and others with more primary care visits $^{20,21}$ or better guideline adherence. ${ }^{22}$

We address prior limitations with a unique dataset that combines a longitudinal study with a state tumor registry database. This linkage allowed for an investigation of the relationship between a cancer diagnosis and cancer screening and provider and patient factors that explain screening behavior.

\section{Methods \\ Population and Sampling}

Participants were from the Wisconsin Longitudinal Study (WLS), a long-term cohort study of a onethird random sample of 1957 Wisconsin high school graduates $(n=10,317)$ and 8,778 of their randomly selected siblings. The WLS is representative of non-Hispanic white men and women with at least 12 years of education, an ethnic/educational subgroup that includes approximately two thirds of the U.S. population in the relevant age bracket. ${ }^{23}$ Participants who responded to the 1992-1993 and 2003-2004 telephone and mail surveys were included ( $\mathrm{n}=8054$ ). Among participants, 1992-1993 response rates for graduates and siblings were $93 \%$ and $87 \%$ for the telephone and $76 \%$ and $77 \%$ for mailed surveys, respectively. To capture incident 
cancer cases, the sample was restricted to Wisconsin residents ( $66 \%$ of participants; $n=5,317$ ).

The WLS was linked to the Wisconsin tumor registry, ${ }^{24}$ allowing for a medical records-based assessment of cancer diagnosis year, site, and SEER summary stage, defined as in situ, localized, regional (direct extension and lymph nodes alone or in combination or not otherwise specified), and distant (metastatic). ${ }^{25,26}$ Participants diagnosed before 1992-1993 (n = 174) or at a "distant" stage $(\mathrm{n}=33)$ were excluded. The sample was further restricted to respondents at the U.S. Preventive Services Task Force minimum recommended age for each of the cancer screening tests (age 40 years for mammogram and 50 years for prostate examination) in place at the time of survey administration, ${ }^{27-29}$ resulting in the exclusion of 15 men. The final sample included 415 participants diagnosed with cancer between 1992-1993 (before cancer) and 2003-2004 (after cancer) and 4680 participants without a cancer diagnosis in the state tumor registry during this time period.

\section{Cancer Screening Variables}

Our dependent variables included 3 cancer screening measures assessed in 2003-2004 (after cancer diagnosis for the cancer group). These questions asked whether participants received a pelvic examination/ Papanicolaou smear, mammogram, or prostate examination within the previous 12 months (yes/no). The first 2 services are recommended by the US Preventive Services Task Force (A/B rating); prostate exams are not ("insufficient evidence" rating). ${ }^{30}$ At the time of the survey, the American Cancer Society recommended annual mammograms, ${ }^{31}$ Papanicolaou/pelvic exams (unless 3 consecutive tests were negative), ${ }^{32}$ and prostate exams ${ }^{33}$ for people in the age range of this cohort.

\section{Explanatory Variables}

The primary explanatory variable was a cancer diagnosis between 1992-1993 and 2003-2004 (yes/no). Provider-, participant-, and cancer-specific factors included (1) provider relationship length (no usual provider; $<5$ years, $5-9$ years, $10-14$ years, or $\geq 15$ years); (2) depressive symptoms (measured in 19921993 and 2003-2004 using the Center for Epidemiologic Studies Depression survey ${ }^{34}$ ); and (3) time since cancer diagnosis (no cancer diagnosis; diagnosed $<5$ years; diagnosed $\geq 5$ years before 2003-2004).

\section{Control Variables}

Analyses were adjusted for factors (measured in 1992-1993) associated with the likelihood of a cancer diagnosis, cancer screening, or both. These factors were chosen on the basis of a cancer stress process model ${ }^{35}$ that relates a cancer diagnosis to subsequent health behaviors and correspond to predisposing, enabling, and need factors included in the Andersen model of health services utilization. $^{36}$

Sociodemographic measures included age, sex, marital status, number of children, education, household income, and employment status. Health measures included self-reported diagnosed chronic conditions with a prevalence more than $10 \%$ in the sample-hypertension; heart disease (heart trouble, circulation problems); respiratory conditions (asthma/ bronchitis/emphysema); and arthritis/rheumatismwith a summary indicator encompassing conditions with less than a $10 \%$ prevalence. Functional status was defined by a condition/illness/disability that limited activities now or was likely to in the future. Self-rated health was assessed as excellent, good, fair, poor, or very poor. A family history of cancer variable indicated whether a participant's biological mother, father, or siblings had been diagnosed with cancer. Health behavior measures included body mass index (underweight/normal, $<24.9 \mathrm{~kg} / \mathrm{m}^{2}$; overweight, 25.0 $29.9 \mathrm{~kg} / \mathrm{m}^{2}$; and obese, $\left.\geq 30 \mathrm{~kg} / \mathrm{m}^{2}\right)^{37}$; physical activity (sedentary, light, moderate, and vigorous) ${ }^{38}$; and cigarette smoking (never, former, current). Insurance status in 2003-2004 was categorized as public or private. Uninsured participants (2\%) were included in the "public" category because of the small sample size and because both groups historically have had reduced health care access and screening rates relative to the privately insured. ${ }^{39}$

Psychosocial measures included personality, stressful life events, social support, and participation. Personality (related to preferences for medical decision making $^{40}$ and provider choice ${ }^{41}$ ) was assessed with a modified version of the 5 -factor model: extraversion, openness to experience, conscientiousness, neuroticism, and agreeableness. ${ }^{42,43}$ Stressful life events were measured with a scale ${ }^{44,45}$ that inventories 18 life events/problems (eg, spousal physical abuse). Social support is a reinforcing factor for preventive care use, ${ }^{46}$ and along with life stress, influences health care use in older adults ${ }^{47}$ and was measured as social participation (a count of participation in 16 social network types, eg, church-connected 
groups) ${ }^{48}$ and social relationships (a count of social get-togethers with friends/relatives in the prior month).

\section{Statistical Analysis}

Data were analyzed using STATA software version 10.0 (StataCorp, LP, College Station, TX). Though the item nonresponse rate averaged across items was low $(2.4 \%)$, multiple imputation by chained equations was employed at the item level. Five imputed datasets were created. Parameter estimates (mean, proportion, regression) and standard errors were obtained using Rubin combination rules. ${ }^{49-53}$ Adjusted multivariable logistic regression models were fit to assess the relationship between a cancer diagnosis and cancer screening. Models were estimated separately for men and women and re-estimated including the "time since diagnosis" group, depressive symptoms after cancer, and provider relationship length variables to determine whether these factors accounted for between-cancer group screening differences. Participants with a history of the cancer being screened for then were excluded to assess whether the relationship between a cancer diagnosis and screening can be explained by screening for recurrence versus second cancers. We accounted for the clustering of sibling and graduate respondents by calculating $95 \%$ confidence intervals using the STATA "robust" command. Statistical significance was defined as $p<.05$.

To aid in interpretation, average predicted probabilities of cancer screening were estimated for the cancer and no cancer groups adjusted to the overall distribution of covariates. Covariate values for a given participant (eg, female, employed) were used to estimate the probability of receiving a given screening test, having or not having cancer under actual and counterfactual scenarios. This was accomplished by first setting all participants' cancer status to 1 (indicating that they had cancer), while maintaining each participant's unique set of other characteristics (eg, age, sex), and averaging individual probabilities across the sample. Next, cancer status was set to 0 for all participants (indicating that they did not have cancer), and the procedure was repeated. The difference in these 2 sets of mean predicted probabilities can be interpreted as the difference in the probability of the given screening between those with cancer and without for a population with the mix of other characteristics present in the sample. A similar approach was followed to calculate average predicted probabili- ties for the 3 "time since diagnosis" groups. To obtain standard errors, individual predicted probability estimates were combined as previously described and averaged, with the process bootstrapped 200 times. The sample drawn during each replication represented a bootstrap sample of clusters.

\section{Results}

Survey participants in 1992-1993 (before cancer) were 53 years old, on average, with relatively high levels of income and education (Table 1). Eightynine percent reported good/excellent health. Participants who went on to receive a cancer diagnosis were significantly more likely than those who did not to be older, male, have a family history of cancer, and have a higher education level.

The most frequently diagnosed cancers were prostate, breast, and colorectal, which were commonly diagnosed at a local stage (Table 2). Fifty-six percent of cancers were diagnosed within 5 years of the 2003-2004 survey. There was moderate variation in the proportion of participants who received cancer screening (Table 3). Proportions ranged from $62 \%$ for Papanicolaou smears/pelvic exams to $76 \%$ for mammograms.

Controlling for factors before cancer and insurance factors, women with cancer were more likely than those without to receive cancer screening (Table 4). Female cancer survivors were more likely to receive Papanicolaou smears/pelvic exams (70\%; 95\% confidence interval [CI], $63 \%$ to $76 \%$ ) and mammograms $(86 \%$; $95 \%$ CI, $78 \%$ to $90 \%$ ) than were women without cancer (61\%; $95 \%$ CI, $59 \%$ to $63 \%$; and $76 \%$; $95 \%$ CI, $74 \%$ to $77 \%$, respectively). Once women with the cancer associated with a given screening test were excluded, the difference for pelvic examination/ Papanicolaou smear remained (69\%; 95\% CI, 63\% to $76 \%$; and $61 \%$; $95 \%$ CI, $59 \%$ to $63 \%$, respectively), though the difference for mammograms was no longer statistically significant $(80 \%$; $95 \%$ CI, $69 \%$ to $86 \%$; and $76 \%$; $95 \%$ CI, $74 \%$ to $77 \%$ ). Among men, cancer survivors were not significantly more likely than men without cancer to receive prostate exams $(76 \% ; 95 \%$ CI, $70 \%$ to $82 \%$; and $69 \%$; $95 \%$ CI, $67 \%$ to $71 \%$, respectively), nor were they more likely to receive them after prostate cancer survivors were excluded (69\%; $95 \%$ CI, $57 \%$ to $77 \%$; and $69 \%$; $95 \%$ CI, $67 \%$ to $71 \%$, respectively). 
Table 1. Key Characteristics of Cancer Cases and No-Cancer Controls at Baseline Assessment $(\mathrm{N}=5095)^{* \dagger}$

\begin{tabular}{|c|c|c|c|c|c|c|c|}
\hline Characteristics & $\begin{array}{c}\text { Overall } \\
(\mathrm{N}=5095)\end{array}$ & $\begin{array}{c}\text { No Cancer } \\
(\mathrm{n}=4680)\end{array}$ & $\begin{array}{l}\text { Cancer } \\
(\mathrm{n}=415)\end{array}$ & Characteristics & $\begin{array}{c}\text { Overall } \\
(\mathrm{N}=5095)\end{array}$ & $\begin{array}{l}\text { No Cancer } \\
(\mathrm{n}=4680)\end{array}$ & $\begin{array}{r}\text { Cancer } \\
(\mathrm{n}=415)\end{array}$ \\
\hline Age & & & & Cigarette smoking & & & \\
\hline$\leq 50$ & 11 & 12 & 5 & Former & 36 & 35 & 41 \\
\hline 51 to 54 & 10 & 10 & 7 & Current & 16 & 16 & 17 \\
\hline 55 to 64 & 64 & 64 & 67 & Physical activity & & & \\
\hline$\geq 65$ & 15 & 15 & 20 & Sedentary/light & 43 & 43 & 43 \\
\hline Female & 55 & 56 & 48 & Moderate & 43 & 43 & 42 \\
\hline Education & & & & Vigorous & 14 & 13 & 15 \\
\hline High school or less & 63 & 63 & 56 & Body mass index & & & \\
\hline Some college & 15 & 14 & 20 & $\leq 24.9$ & 32 & 32 & 30 \\
\hline College degree & 12 & 12 & 13 & $25-29$ & 43 & 43 & 45 \\
\hline $\begin{array}{l}\text { Postgraduate } \\
\text { training }\end{array}$ & 10 & 10 & 12 & $\geq 30$ & 25 & 25 & 25 \\
\hline Insurance status* & & & & Family history of cancer & 57 & 56 & 64 \\
\hline Private & 54 & 54 & 47 & Marital status & & & \\
\hline Public/uninsured $^{\dagger}$ & 46 & 46 & 53 & $\begin{array}{l}\text { Widowed/divorced/never } \\
\text { married }\end{array}$ & 15 & 15 & 13 \\
\hline Household income (\$) & & & & Married & 85 & 85 & 87 \\
\hline$<20,000$ & 15 & 15 & 15 & Mean number of children & $3(2)$ & $3(2)$ & $3(2)$ \\
\hline $20,000-34,999$ & 13 & 13 & 13 & Mean stressful life event count & $2(2)$ & $2(2)$ & $2(2)$ \\
\hline $35,000-49,999$ & 20 & 20 & 20 & Mean social relationship count & $8(6)$ & $8(6)$ & $8(7)$ \\
\hline $50,000-64,999$ & 19 & 19 & 19 & Mean social participation count & $4(3)$ & $4(3)$ & $4(3)$ \\
\hline$\geq 65,000$ & 34 & 33 & 33 & Personality score (Mean) & & & \\
\hline Percent employed & 84 & 84 & 85 & Openness to experience & $21(5)$ & $21(5)$ & $22(5)$ \\
\hline Chronic conditions & & & & Conscientiousness & $29(4)$ & $29(4)$ & $29(4)$ \\
\hline Hypertension & 23 & 23 & 26 & Extraversion & $23(5)$ & $23(5)$ & $23(5)$ \\
\hline Heart disease & 10 & 10 & 12 & Agreeableness & $29(4)$ & $29(4)$ & $28(4)$ \\
\hline $\begin{array}{l}\text { Respiratory } \\
\text { conditions }\end{array}$ & 10 & 10 & 9 & Neuroticism & $16(5)$ & $16(5)$ & $16(5)$ \\
\hline Arthritis & 26 & 26 & 29 & & & & \\
\hline Other diagnoses & 22 & 22 & 21 & & & & \\
\hline Functional limitation & 17 & 17 & 16 & & & & \\
\hline \multicolumn{8}{|l|}{ Self-rated health } \\
\hline Very poor/poor/fair & 11 & 11 & 12 & & & & \\
\hline Good & 63 & 63 & 64 & & & & \\
\hline Excellent & 26 & 26 & 25 & & & & \\
\hline
\end{tabular}

Values represent percent (ages) unless specified as mean (standard deviation). Bolded values indicate statistically significant difference between respondents with and without cancer $(p<.05)$.

*Measured at the time of the 2003-2004 survey.

${ }^{\dagger}$ Two percent of participants were uninsured at the time of the survey.

The association between a cancer diagnosis and cancer screening differed by the amount of time a person had cancer. Within 5 years of diagnosis, cancer survivors were more likely than controls to have had cancer screening tests other than for prostate cancer. However, the only difference in cancer screening among longer-term survivors compared to no-cancer controls was for mammograms $(86 \%$;
$95 \%$ CI, $78 \%$ to $92 \%$; and $76 \%$; $95 \%$ CI, $74 \%$ to $77 \%$, respectively) (Table 4). Once participants with a history of the cancer associated with the screening test were excluded, there were few significant differences for short-term survivors and no significant differences for longer-term cancer survivors compared with no-cancer controls. The magnitude of the differences described remained 
Table 2. Cancer in the Wisconsin Longitudinal Study by Site, Stage, and Time Since Diagnosis $(\mathrm{N}=415)$

\begin{tabular}{lc}
\hline Cancer Characteristic & $\mathrm{n}(\%)$ \\
\hline Time between diagnosis and survey (years) & \\
$0-4$ & $231(56)$ \\
$\geq 5$ & $184(44)$ \\
Cancer site at diagnosis & \\
Prostate & $133(32)$ \\
Breast & $113(27)$ \\
Colorectal & $39(9)$ \\
Bladder & $14(3)$ \\
Lung & $10(2)$ \\
Other & $106(26)$ \\
Cancer stage at diagnosis & \\
In situ & $38(9)$ \\
Local & $277(67)$ \\
Regional & $83(20)$ \\
Missing & $17(4)$ \\
\hline
\end{tabular}

Participants with cancers diagnosed at a distant stage were excluded from the analysis.

when after-cancer provider and patient factors were included in the models.

\section{Discussion}

To our knowledge, this is the first study to prospectively assess the relationship between a cancer diagnosis and cancer screening in short- and longer-term survivors while exploring a comprehensive set of provider-, patient-, and cancer-specific factors that might explain observed relationships. Although the majority of cancer survivors received recommended cancer screening, there was important variation by screening type. Overall, cancer survivors were more likely than people without cancer to receive cancer screening, with propor- tions that changed little with adjustment. However, once participants who had the cancer associated with a given screening test were excluded, the only statistically significant difference was higher Papanicolaou smears/pelvic exams for short-term cancer survivors. There were no differences in cancer screening among long-term survivors relative to no-cancer controls. The magnitude of these relationships did not change when depressive symptoms or provider-patient relationship length after cancer were included in the models.

It is encouraging and not surprising that cancer survivors were more likely than participants without cancer to receive the screening test associated with their cancer within 5 years of diagnosis because this likely represents screening for recurrence. Twenty percent to $30 \%$ of cancer survivors did not undergo screenings for other cancer types, however, despite evidence that many cancer survivors remain at risk of developing second primary cancers. ${ }^{5,54}$ This gap between recommended care and actual practice has been demonstrated in other studies. ${ }^{8,12}$ There were no significant differences from controls in the receipt of any of the cancer screening services $\geq 5$ years from the time of diagnosis, again suggesting the influence on results of screening for recurrence within 5 years of diagnosis.

Given the health risks, one might expect cancer survivors to be more likely to follow screening guidelines than people without cancer. One explanation for lack of adherence may be access to care. However, our study cohort had few uninsured participants; even then, cancer screening rates were no better than national rates for breast cancer survivors. ${ }^{11}$ This suggests that better access to care and higher socioeconomic status do not necessarily

Table 3. Descriptive Statistics for Dependent Variables

\begin{tabular}{lccc}
\hline Characteristic & Overall, $\mathrm{n}(\%)(\mathrm{n}=5095)$ & No Cancer, $\mathrm{n}(\%)(\mathrm{n}=4680)$ & Cancer, $\mathrm{n}(\%)(\mathrm{n}=415)$ \\
\hline Cancer screening & & & \\
Pelvic exam or Pap smear & $2797(62)$ & $2599(61)$ & $198(69)$ \\
Mammogram & $2797(76)$ & $2599(76)$ & $198(87)$ \\
Prostate exam $_{\text {Cancer screening }}^{\dagger}$ & $2298(70)$ & $2081(69)$ & $217(79)$ \\
Pelvic exam or Pap smear & - & - & $195(68)$ \\
Mammogram & - & - & $88(81)$ \\
Prostate exam & - & - & $85(72)$ \\
\hline
\end{tabular}

*Pelvic/Pap and mammogram for women only, prostate exam for men only.

${ }^{\dagger}$ Excludes participants with cancer associated with screening. 


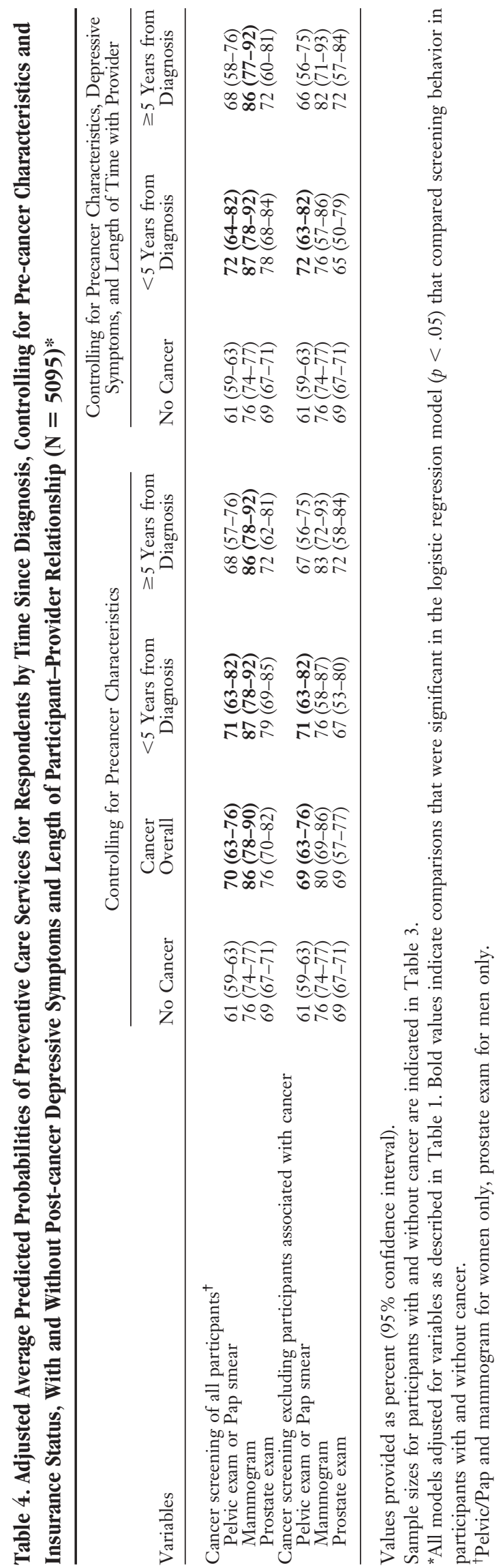

translate into preventive service guideline adherence. A second explanation may be related to provider type. Ninety-one percent of cancer survivors identified a PCP as their usual provider. Rates of non-cancer-related preventive care utilization have been shown to be higher for cancer survivors who see PCPs, whereas survivors who see oncologists receive more cancer screening, ${ }^{7,15,55}$ which may account for some of the observed effects.

It is noteworthy that adjusting for a comprehensive set of factors did little to affect cancer screening probabilities in the study cohort. Instead, probabilities were most impacted by cancer-related factors (site and time since diagnosis). Depressive symptoms may not impact cancer screening behavior in this cohort because of the relatively high levels of access to care coupled with long-standing provider relationships in the cancer and no cancer groups (10.4 and 10.7 years, respectively).

Some study limitations that should be noted. First, though US Preventive Services Task Force recommended age thresholds for cancer screening in place at the time of survey administration were used, ${ }^{27-29}$ thresholds for some of the screening services under investigation have changed. Prostate cancer screening is no longer recommended for men older than 75 years, nor is mammography for women after age 75 to 85 years or cervical cancer screening after age 65 years (unless patients is otherwise at risk or had adequate prior screening). However, given the higher risks of secondary cancers faced by many cancer survivors, one would expect cancer survivors to be more likely than people without cancer to receive cancer screening. This was not found to be the case for longerterm cancer survivors once participants were excluded who had a history of the cancer being screened for. Second, this study relied on selfreported cancer screening. Correlations between self-reported and medical-record-based assessments of cancer screening however are moderate to high. ${ }^{56}$ Third, our study did not have information about recurrence or treatment. For participants undergoing cancer treatment, not undergoing screening for a cancer type other than their own may reflect energies rightly directed toward treatment. However, this is unlikely to explain all study findings because significant differences in screening between the cancer and no-cancer control groups were primarily seen within the first 5 years of diagnosis, when the 
majority of survivors would likely be undergoing treatment and surveillance for cancer recurrence. Fourth, colon cancer screening was not available in the WLS. Therefore, the only follow-up cancer screening assessed in men was prostate cancer screening. Last, the sample size of cancer survivors precluded the examination of interaction effects and may have contributed to the lack of differences observed for analyses that excluded cervical cancer survivors.

Despite these limitations, the current study found that although the majority of cancer survivors receive recommended care, there remains room for improvement. Survivorship care plans that detail recommended follow-up care have been suggested as a mechanism to facilitate providerpatient communication. ${ }^{4}$ Given that 5 years from diagnosis nearly two thirds of cancer survivors visit their PCP exclusively, ${ }^{15}$ a plan such as this could provide additional opportunities for clear communication between health care providers (eg, oncologists and PCPs). Because only $28 \%$ of breast cancer survivors report good communication between their PCP and oncologist ${ }^{57}$ and more than half of PCPs rate the transfer of care between oncologists and PCPs as poor, ${ }^{58}$ a survivorship care plan has the potential to align provider and patient expectations and optimize care delivery and healthy outcomes for cancer survivors.

\section{References}

1. Jemal A, Murray T, Ward E, et al. Cancer statistics, 2005. CA Cancer J Clin 2005;55(1):10-30.

2. Jemal A, Clegg LX, Ward E, et al. Annual report to the nation on the status of cancer, 1975-2001, with a special feature regarding survival. Cancer 2004;101:3-27.

3. Ganz PA. Late effects of cancer and its treatment. Semin Oncol Nurs 2001;17:241-8.

4. Hewitt M, Greenfield S, Stovall E, eds. From cancer patient to cancer survivor: lost in transition. Washington, D.C.: Institutes of Medicine, National Research Council of the National Academies, The National Academies Press; 2006.

5. Khan NF, Ward A, Watson E, Austoker J, Rose PW. Long-term survivors of adult cancers and uptake of primary health services: a systematic review. Eur J Cancer 2008;44:195-204.

6. Bellizzi KM, Rowland JH, Jeffery DD, McNeel T. Health behaviors of cancer survivors: examining opportunities for cancer control intervention. J Clin Oncol 2005;23:8884-93.
7. Earle CC, Burstein HJ, Winer EP, Weeks JC. Quality of non-breast cancer health maintenance among elderly breast cancer survivors. J Clin Oncol 2003; 21:1447-51.

8. Trask PC, Rabin C, Rogers ML, et al. Cancer screening practices among cancer survivors. Am J Prev Med 2005;28:351-6.

9. Snyder CF, Frick KD, Peairs KS, et al. Comparing care for breast cancer survivors to non-cancer controls: a five-year longitudinal study. J Gen Intern Med 2009;24:469-74.

10. Earle CC, Neville BA. Under use of necessary care among cancer survivors. Cancer 2004;101:1712-9.

11. Duffy CM, Clark MA, Allsworth JE. Health maintenance and screening in breast cancer survivors in the United States. Cancer Detect Prev 2006;30:52-7.

12. Mayer DK, Terrin NC, Menon U, et al. Screening practices in cancer survivors. J Cancer Surviv 2007; $1: 17-26$.

13. Aziz NM, Rowland JH. Trends and advances in cancer survivorship research: challenge and opportunity. Semin Radiat Oncol 2003;13:248-66.

14. Bloom JR, Stewart SL, D'Onofrio CN, Luce J, Banks PJ. Addressing the needs of young breast cancer survivors at the 5 year milestone: can a short-term low intensity intervention produce change? J Cancer Surviv 2008;2:190-204.

15. Snyder CF, Earle CC, Herbert RJ, Neville BA, Blackford AL, Frick KD. Preventive care for colorectal cancer survivors: a 5-Year longitudinal study. J Clin Oncol 2008;26:1073-9.

16. Fenton JJ, Franks P, Reid RJ, Elmore JG, Baldwin LM. Continuity of care and cancer screening among health plan enrollees. Med Care 2008;46:58-62.

17. Kiefe CI, Funkhouser E, Fouad MN, May DS. Chronic disease as a barrier to breast and cervical cancer screening. J Gen Intern Med 1998;13:357-65.

18. Zabora J, Brintzenhofeszoc K, Curbow B, Hooker C, Piantadosi S. The prevalence of psychological distress by cancer site. Psychooncology 2001;10:19-28.

19. Thorpe JM, Kalinowski CT, Patterson ME, Sleath BL. Psychological distress as a barrier to preventive care in community-dwelling elderly in the United States community-dwelling elderly. Med Care 2006;44:187-91.

20. Vedsted P, Fink P, Olesen F, Munk-Jorgensen P. Psychological distress as a predictor of frequent attendance in family practice: a cohort study. Psychosomatics 2001;42:416-22.

21. Rowan PJ, Davidson K, Campbell JA, Dobrez DG, MacLean DR. Depressive symptoms predict medical care utilization in a population-based sample. Psychol Med 2002;32:903-8.

22. Green CA, Pope CR. Depressive symptoms, health promotion, and health risk behaviors. Am J Health Promot 2000;15:29-34.

23. U.S. Bureau of the Census. Educational attainment in the United States: March 2000. Series 
P-20, no. 536. Washington, D.C.: Government Printing Office; 2000.

24. Wisconsin Cancer Reporting System. Wisconsin cancer incidence and mortality, 2000-2004. Madison, WI: Bureau of Health Information and Policy, Division of Public Health, Wisconsin Department of Health and Family Services; 2007.

25. Shambaugh EM, Weiss M, Axtell LM. Summary staging guide for the cancer Surveillance, Epidemiology and End Results Reporting (SEER) program. Bethesda, MD: U.S. Department of Health, Education, and Welfare, Public Health Service, National Institutes of Health; 1977.

26. Young JL Jr, Roffers SD, Ries LAG, Fritz AG, Herlbut AA, eds. SEER summary staging manual-2000. Codes and coding instructions. Bethesda, MD: National Cancer Institute; 2001.

27. United states Preventive Services Task Force. Screening for prostate cancer: recommendations and rationale. Rockville, MD: Agency for Healthcare Research and Quality; 2002.

28. United States Preventive Services Task Force. Screening for breast cancer: recommendations and rationale. Rockville, MD: Agency for Healthcare Research and Quality; 2002.

29. United States Preventive Services Task Force. Screening for cervical cancer: recommendations and rationale. Rockville, MD: Agency for Healthcare Research and Quality; 2003.

30. United States Preventive Services Task Force. Guide to clinical preventive services. Available from: http:// www.ahrq.gov/clinic/cps3dix.htm. Accessed July 26, 2009.

31. Smith RA, Saslow D, Sawyer KA, et al. American cancer society guidelines for breast cancer screening: update 2003. CA Cancer J Clin 2003;53:141-69.

32. Saslow D, Runowicz CD, Solomon D, et al. American Cancer Society guideline for the early detection of cervical neoplasia and cancer. CA Cancer J Clin 2002;52:342-62.

33. Smith RA, von Eschenbach AC, Wender R, et al. American Cancer Society guidelines for the early detection of cancer: update of early detection guidelines for prostate, colorectal, and endometrial cancers. Also: update 2001-t Testing for early lung cancer detection. CA Cancer J Clin 2001;51: $38-75$.

34. Radloff LS. The CES-D scale: a self-report depression scale for research in the general population. Appl Psychol Meas 1977;1:385-401.

35. Bowman KF, Smerglia VL, Deimling GT. A stress model of cancer survivorship in older long-term survivors. J Ment Health Aging 2004;10:1-21.

36. Andersen RM. Revisiting the behavioral model and access to medical care: does it matter? J Health Soc Behav 1995;36:1-10.

37. National Institutes of Health, National Heart, Lung, and Blood Institute. Clinical guidelines on the identi- fication, evaluation, and treatment of overweight and obesity in adults. Report no. 98-4083. Bethesda, MD: United States Department of Health and Human Services, Public Health Service; 1998.

38. Østbye T, Taylor DH, Jung SH. A longitudinal study of the effects of tobacco smoking and other modifiable risk factors on ill health in middle-aged and old Americans: results from the Health and Retirement Study and Asset and Health Dynamics Among the Oldest Old survey. Prev Med 2002;34:334-45.

39. Swan J, Breen N, Coates RJ, Rimer BK, Lee NC. Progress in cancer screening practices in the United States: results from the 2000 National Health Interview Survey. Cancer 2003;97:1528-40.

40. Flynn KE, Smith MA. Personality and health care decision-making style. J Gerontol B Psychol Sci Soc Sci 2007;62:P261-7.

41. Everett CM, Schumacher JR, Wright A, Smith MA. Physician assistants and nurse practitioners as a usual source of care. J Rural Health 2009;25:407-14.

42. Briggs SR. Assessing the five-factor model of personality description. J Pers 1992;60:253-93.

43. Costa PT Jr, McCrae RR. Normal personality assessment in clinical practice: the NEO Personality Inventory. Psychol Assess 1992;4:5-13.

44. Borkowski JG, Benton AL, Spreen O. Word fluency and brain damage. Neuropsychologia 1967;5:135-40.

45. Turner RJ, Lloyd DA. Lifetime traumas and mental health: the significance of cumulative adversity. J Health Soc Behav 1995;36:360-76.

46. Walsh JME, Mcphee SJ. A systems model of clinical preventive care: an analysis of factors influencing patient and physician. Health Educ Q 1992;19:157-75.

47. Counte MA, Glandon GL. A panel study of life stress, social support, and the health services utilization of older persons. Med Care 1991;29:348-61.

48. Brand JE, Burgard SA. Effects of job displacement on social participation: findings over the life course of a cohort of joiners. Report no. 07-623. Ann Arbor, MI: Population Studies Center, University of Michigan Institute for Social Research; 2007.

49. Rubin DB. Multiple imputation for nonresponse in surveys. New York: John Wiley \& Sons; 1987.

50. Rubin DB. Multiple imputation after $18+$ years. J Am Stat Assoc 1996;91:473-89.

51. Schafer JL. Analysis of incomplete multivariate data. London, England: Chapman \& Hall; 1997.

52. Royston P. Multiple imputation of missing values. Stata J 2004;4:227-41.

53. Royston P. Multiple imputation of missing values: update. Stata J 2005;5:188-201.

54. Matesich SMA, Shapiro CL. Second cancers after breast cancer treatment. Semin Oncol 2003;30:740-8.

55. Keating NL, Landrum MB, Guadagnoli E, Winer EP, Ayanian JZ. Factors related to underuse of surveillance mammography among breast cancer survivors. J Clin Oncol 2006;24:85-94. 
56. Martin LM, Leff M, Calonge N, Garrett C, Nelson DE. Validation of self-reported chronic conditions and health services in a managed care population. Am J Prev Med 2000;18:215-8.

57. Mao JJ, Bowman MA, Stricker CT, et al. Delivery of survivorship care by primary care physicians: the perspective of breast cancer patients. J Clin Oncol 2009;27:933-8.

58. Nissen MJ, Beran MS, Lee MW, Mehta SR, Pine DA, Swenson KK. Views of primary care providers on follow-up care of cancer patients. Fam Med 2007; 39:477-82. 